The 13th International Conference on Brain Energy Metabolism: "How Metabolism Dictates Neurotransmission, Function and Behavior"

Barros, L Felipe; Schousboe, Arne; McKenna, Mary C

Published in:

Journal of Neuroscience Research

DOI:

10.1002/jnr.24445

Publication date:

2019

Document version

Publisher's PDF, also known as Version of record

Document license:

CC BY

Citation for published version (APA):

Barros, L. F., Schousboe, A., \& McKenna, M. C. (2019). The 13th International Conference on Brain Energy Metabolism: "How Metabolism Dictates Neurotransmission, Function and Behavior". Journal of Neuroscience Research, 97(8), 849-853. https://doi.org/10.1002/jnr.24445 


\title{
The 13th International Conference on Brain Energy Metabolism: "How Metabolism Dictates Neurotransmission, Function and Behavior"
}

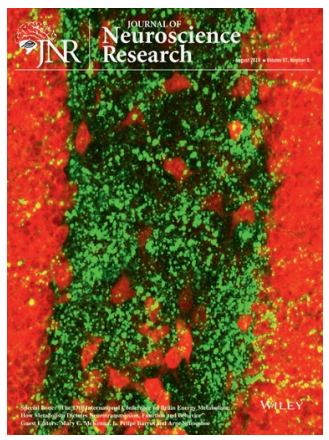

\author{
L. Felipe Barros ${ }^{1}$ | Arne Schousboe ${ }^{2}$ (D) | Mary C. McKenna ${ }^{3}$ (D) \\ ${ }^{1}$ Laboratory of Biology, Centro de Estudios Cientificos, Valdivia, Chile \\ ${ }^{2}$ Department of Drug Design \& Pharmacotherapy, School of Pharmaceutical Sciences, University of Copenhagen, Copenhagen, Denmark \\ ${ }^{3}$ Department of Pediatrics and Program in Neuroscience, University of Maryland School of Medicine, Baltimore, Maryland
}

Correspondence

Mary C. McKenna, Department of Pediatrics, University of Maryland School of Medicine, 655 W. Baltimore St., Room 13-019, Baltimore, MD 21201.

Email: mmckenna@som.umaryland.edu

Funding information

National Institute of Neurological Disorders and Stroke, Grant/Award Number: R13 NS106919

The 13th International Conference on Brain Energy Metabolism, entitled, "How Metabolism Dictates Neurotransmission, Function and Behavior" was held on March 7-10, 2018 in the scenic and historic city of Valdivia in the Los Rios region of Chile. The conference was hosted by L. Felipe Barros at the Carpa de la Ciencia of the Center for Scientific Studies (Centro de Estudios Científicos, CECS), a private, nonprofit corporation devoted to the development, promotion, and diffusion of scientific research. Previous meetings of this highly successful series of International Conferences on Brain Energy Metabolism (ICBEM) were also held in beautiful surroundings, the first in Carcassonne, France in 1993, followed by Blaubeuren, Germany, 1995; Waterville Valley, New Hampshire, USA, 1997; Oxford, UK, 1999; Trondheim, Norway, 2001; Heraklion, Crete, 2004; Lausanne, Switzerland, 2006; Beijing, China, 2008; Budapest, Hungary, 2010; Monterey, California, USA, 2012; Helsinge, Denmark, 2014; and Hong Kong, China in 2016.

The conference was attended by 105 students, postdocs, and investigators from 16 countries in Europe, North and South America, Asia, and Australia. Travel awards were provided from conference funds from the National Institute of Neurological Disorders and Stroke (NINDS), International Society for Cerebral Blood Flow and Metabolism (ISCBFM), and the International Society for Neurochemistry (ISN) for a total of 24 graduate students, trainees and postdoctoral fellows from 10 countries. The travel awardees were from Argentina, Chile, Canada, Denmark, France, Germany, Switzerland, the United Kingdom, Uruguay, and the United States.

Edited by L.Felipe Barros, Mary C. McKenna, Arne Schousboe.

All peer review communications can be found with the online version of the article.
The conference began on March 7 with a scholarly keynote address by Gerald Dienel who gave a comprehensive historical introduction to the exciting and clinically relevant subject of activitydependent aerobic glycolysis in the brain. Dr. Dienel's talk generated considerable discussion that continued at the opening reception and throughout the meeting.

The sessions, which covered a wide range of topics, included 20 talks, 4 of which were presented by young investigators. Noted investigators in the fields of brain energy metabolism and neurodegeneration chaired the scientific sessions with a student or postdoc as co-chair. There were eight formal sessions each with 2-3 speakers presenting 20-min talks. In the tradition of the ICBEM meetings about one third of the time for each session was devoted to discussion of speakers' presentations and session content. The formal sessions focused on $\mathrm{O}_{2}$ metabolism and sensing, bioenergetics and mitochondrial metabolism, mitochondrial trafficking, mitochondria/ energy production/ROS, NAD ${ }^{+}$homeostasis and salvage pathways, glycogen role and relationship to glucose metabolism and neurotransmission, neuronal-glial interactions modulating neurotransmission, wakefulness and injury, and a very interesting session dedicated to the novel topic of the reciprocal relationship between metabolism and behavior. In the true spirit of this cutting-edge meeting, several talks challenged the current understanding of metabolism in astrocytes and neurons and all the speakers provided new insights into the regulation and roles of metabolism in brain (Figure 1 ).

The first full day of the conference began with a talk on "25 Years of ICBEM History" by Mary McKenna honoring the 25th anniversary of the first ICBEM meeting in Carcassonne, France in 1993. This was followed by a tribute to the late Leif Hertz, a pioneer in 


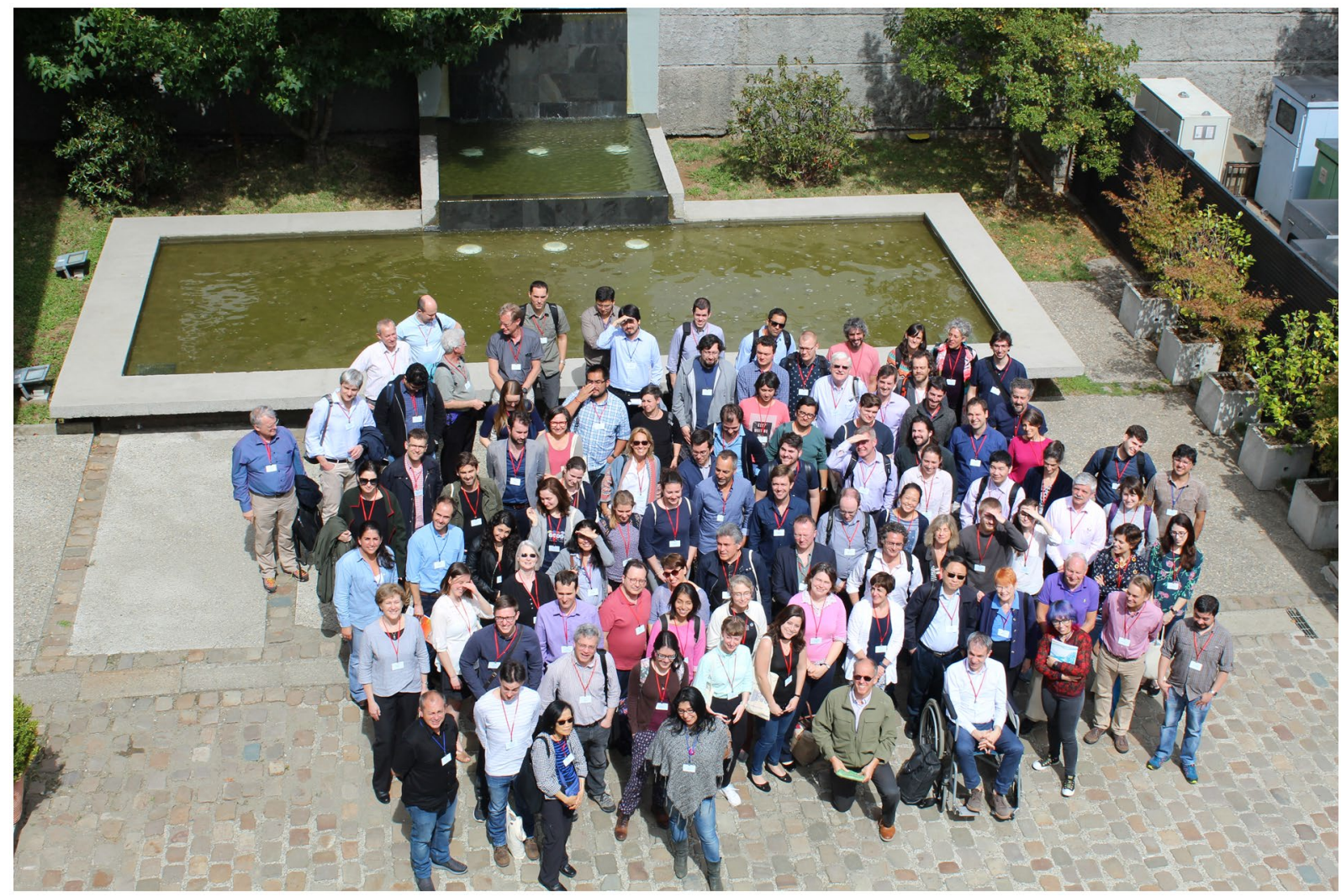

FIGURE 1 Attendees from 16 countries throughout the world at the 13th ICBEM conference Valdivia, Chile 2018

brain metabolism whose key studies laid the foundation for studies using primary cultures to determine the properties of astrocytes and glutamatergic and GABAergic neurons from brain given by Mary McKenna and Arne Schousboe.

The first day included an exciting session on $\mathrm{O}_{2}$ metabolism and sensing that included an innovative talk by Sergey Vinogradov showing how the most recent generation of two-photon probes can be used for dynamic imaging of oxygen in the brain. Alexander Gourine's thought provoking talk included data suggesting that astrocytes are functionally specialized CNS metabolic sensors tuned for rapid detection of physiological changes in brain $\mathrm{PO}_{2}, \mathrm{PCO}_{2}$, and $\mathrm{pH}$. Ray Swanson focused on the intriguing topic of how variations in energy metabolism and substrate availability influence microglial function.

The second session was the much anticipated and highly competitive student awardee presentations that were selected based on the quality of their abstracts. Talks (7 min +3 min question period) were presented by Anna Hadjihambi (UK), Antoine Cherix (Switzerland), Elisa York (Canada), Emil Jakobsen (Denmark), Marianne Maugard (France), Ernesto Miquel (Uruguay), Nina Klimova (USA), Felipe Baeza Lehnert (Chile), Zoe Looser (Switzerland), Jens Andersen (Denmark), Sarah Rice (USA), and Ignacio Fernández-Moncada (Chile). These presentations were all first rate and were highly regarded by conferees. Two of these students were selected to receive a certificate and small prize sponsored by the Journal of Neuroscience Research. The outstanding talks by students and postdocs served to remind all conference attendees that the future of the field and this conference is very promising. After lunch, attendees were excited to hear the 21 two-minute pitches from students, postdocs, and trainees on "Why you should come to my poster". All 47 posters were presented at 2-hr evening sessions on the first and second days of the meeting accompanied by wonderful refreshments from the local Chilean company Colun. All posters were on display throughout the entire meeting which enabled additional discussions among conferees during the breaks and lunch time. Two of the student posters were also selected to receive certificates and prizes sponsored by the Journal of Neuroscience Research (Figure 2).

A highlight of the second full day was the Special Imaging talk by Dr. Zu Hang Sheng, who is using modern fluorescent reporters to bridge the gap between the fields of mitochondrial biology and mitochondrial metabolism. Others in the mitochondrial trafficking session included Mike Robinson who focused on the physiologic and pathologic implications of functional interactions between astrocytic glutamate transport, calcium, and mitochondria, and Gary Yellen who presented interesting novel findings of neuronal metabolism using an NADH sensor.

The session on mitochondria/oxidative stress/ROS included interesting new findings from Juan Bolaños on the role of astrocytes and neurons in determining brain redox bioenergetics, and from Margaret Rice on the role of hydrogen peroxide $\left(\mathrm{H}_{2} \mathrm{O}_{2}\right)$ in dynamic regulation of neuronal activity and transmitter release via ATP-sensitive $\mathrm{K}^{+}\left(\mathrm{K}_{\text {ATP }}\right.$ ) channels and TRPM2 cation channels. There was great interest in the timely session on $\mathrm{NAD}^{+}$homeostasis and 


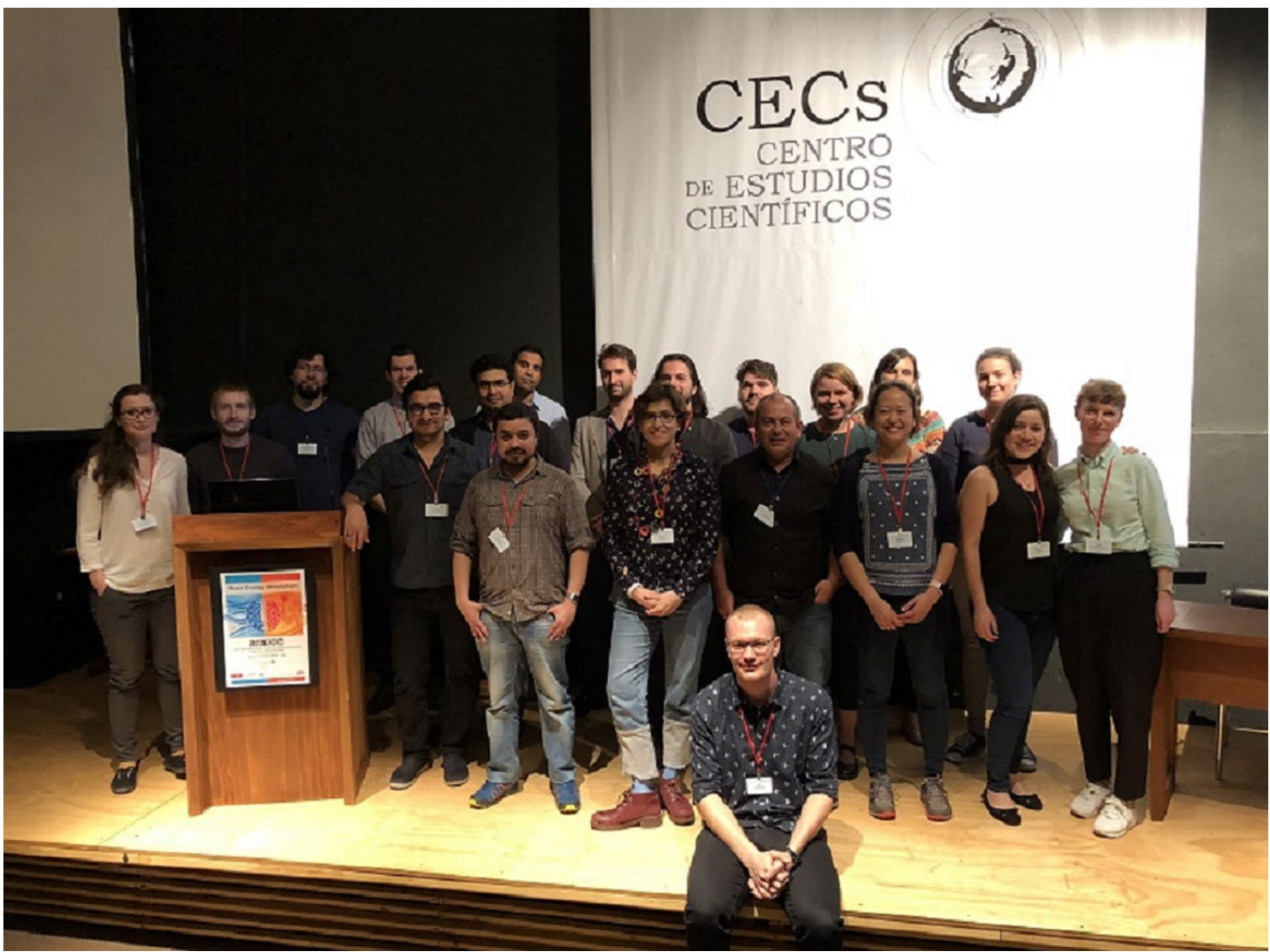

FIGURE 2 Students, postdocs, and trainees ready to give their 2-min pitches on "Why you should come to my poster"

salvage pathways. Tibor Kristian spoke on the effects of nicotinamide mononucleotide (NMN) in ameliorating ischemic brain damage, and Marcelo Vargas reported how enhancing $\mathrm{NAD}^{+}$salvage in astrocytes could prevent astrocyte-mediated motor neuron death. Felipe Court from Chile presented novel findings on how Schwann cell exosomes mediate neuron-glia communication and enhance axonal regeneration.

The session on bioenergetics and mitochondrial metabolism included a clinical talk by neurologist Charlotte Stagg, from Oxford, UK, on her recent studies elucidating the role of glutamate, GABA and glutamine metabolism in brain plasticity and neurological recovery. Lindy Rae gave a thought-provoking talk showing data that challenged many of the assumptions on acetate and $\beta$-hydroxybutyrate metabolism in brain. Jakob Nissen's talk made attendees consider if glutamate metabolism via glutamate dehydrogenase is important for brain mitochondrial metabolism.

The session on glycogen was interesting and timely since glycogen was one of the topics for the evening discussion sessions on the second day of the conference. Hajime Hirase from Japan presented elegant and beautiful glycogen immunohistochemistry (featured on the cover of this issue) showing brain region-dependent glycogen accumulation and possibly metabolic heterogeneity of astrocytes. Jordi Duran presented data that change the current view of the role of glycogen in the brain and reveal that endogenous neuronal glycogen metabolism is important in certain conditions.

The second evening of the conference followed the tradition of the 11th meeting in Denmark of in having a 2-hr small Group Discussion, with sessions on topics selected by Ray Swanson and Blanca Aldana. Topics included cell-specific and subcellular energy metabolism, mitochondria and neurological disease, and glycogen. These sessions were highly interactive discussions and sometimes debates focused on topics proposed by the conference attendees.

The session on neuronal-glial interactions modulating neurotransmission, wakefulness and injury provided interesting new insights into metabolism. Detlev Boison presented mechanisms by which astroglial adenosine metabolism and signaling affects neuronal plasticity, how dysfunction of astroglial adenosine metabolism may contribute to epilepsy and schizophrenia, and the translational potential of metabolic therapeutic strategies aimed at restoration of normal adenosine metabolism. Kelly Drew's talk focused on the seasonal rhythm in $A_{1}$ adenosine receptor signaling in specific brain regions in regulating hibernation of arctic ground squirrels. Sandra Hewett's data, showing that system $x_{c}^{-}$contributes to, rather than protects against, 3-nitroproprionic acid-induced symptomology and pathology in female mice, underscored the importance of studying both female and male brains. 
An exciting new session with talks by young investigators focused on how metabolism influences behavior. Claire Rittschof gave a fascinating talk on honey bee aggression showing how changes in brain energy metabolism predicts behavior and responds to social cues. Using genetic manipulations of the activity of the pyruvate dehydrogenase complex, Pierre-Yves Plaçais described how the upregulation of mushroom body energy flux is both necessary and sufficient to drive long-term memory formation. The last session had presentations by three postdocs who were selected based on the quality of their abstracts. Carlos Díaz-García from Gary Yellen's lab showed how synaptic stimulation increases glucose utilization in dentate granule neurons. Kelly Chamberlain from Zu Hang Sheng's lab showed exciting work showing that oligodendrocytes directly affect local axonal bioenergetics through a new pathway that does not involve lactate. Louis-Philippe Bernier from Brian MacVicar's lab showed that microglia have a unique cellular metabolic signature and are capable of rapidly adapting their energy usage to various substrates available in their environment. The quality of these presentations confirmed that an outstanding group of young investigators are poised to make key contributions to the understanding of brain energy metabolism.

Conference attendees enjoyed the scientific sessions as well as the ambiance of both CECS and the Hotel Dreams that allowed participants to meet informally and discuss research ideas. During a break in the conference attendees hiked through a temperate rain forest filled with beautiful ferns, flowers, trees, and wildlife to a scenic vista overlooking the Pacific Ocean. On Saturday evening, the participants enjoyed a scenic boat ride down the river followed by a closing dinner of delicious Chilean grilled meats and other cuisine at a lovely restaurant on the river. The meal was followed by great music and lots of dancing (Figure 3).

We thank the members of the program committee led by Mary C. McKenna (Chair, Baltimore, MD, USA) and L. Felipe Barros (Vice Chair, Valdivia, Chile), for putting together an outstanding program. The organizing committees included both junior and senior scientists, with new members to bring fresh points of view and vitality to the program. Several of the members of the program committee including the conference chair had been involved in the planning of previous meetings. Gilles Bonvento (Paris, France), Mauro DiNuzzo (Copenhagen, Denmark), Kelly Drew (Fairbanks, AK, USA), Susanna Scafidi (Baltimore, MD, USA), and Bruno Weber (Zurich, Switzerland) joined the committee for the first time to ensure that new ideas for the program were included. Johannes Hirrlinger (Leipzig, Germany), Caroline Rae (Sydney, Australia), Michael Robinson (Philadelphia, PA, USA), Ray Swanson (San Francisco, CA, USA), Arne Schousboe (Copenhagen, Denmark), Helle Waagepetersen (Copenhagen, Denmark), Albert Yu (Beijing, China), and João Duarte (Lund, Sweden) were chosen for their acknowledged leadership in brain cell signaling, brain biochemistry, membrane transport, and NMR studies in health and disease.

The local organizing committee included young researchers from the host organization and local universities. We thank the members of this committee including L. Felipe Barros (Chair), Felipe Amtmann, Felipe Baeza-Lehnert, Yasna Contreras, Loreto

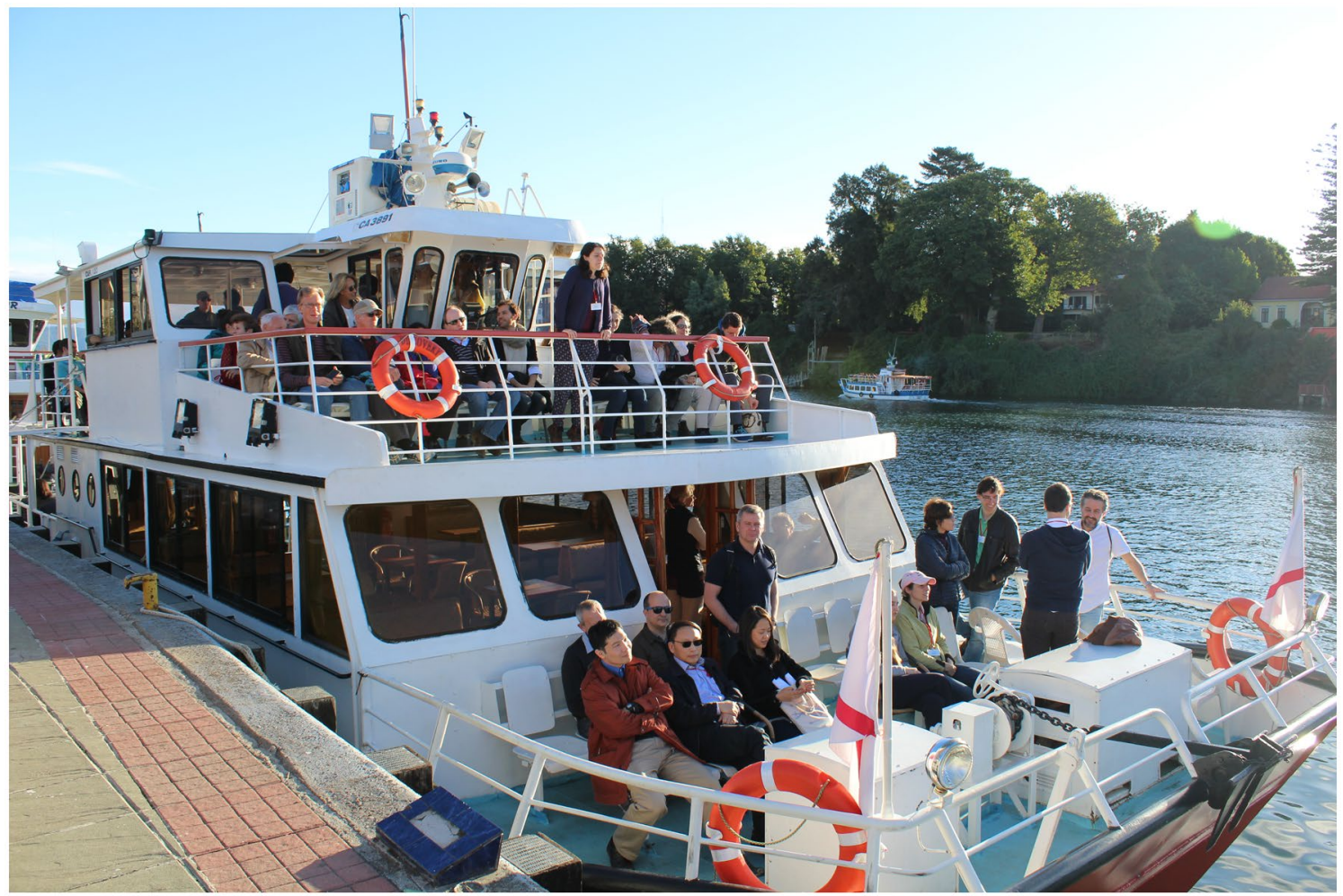

FIGURE 3 Everybody on board! Forty minutes up the Calle-Calle river to the Closing Dinner: asado a la Chilena, robust red wines, toasting and dancing to relax after 4 days of intense and productive scientific exchange. Farewell to ICBEM Valdivia 2018, see you at the 14th ICBEM conference in Hilton Head, South Carolina in 2020! 


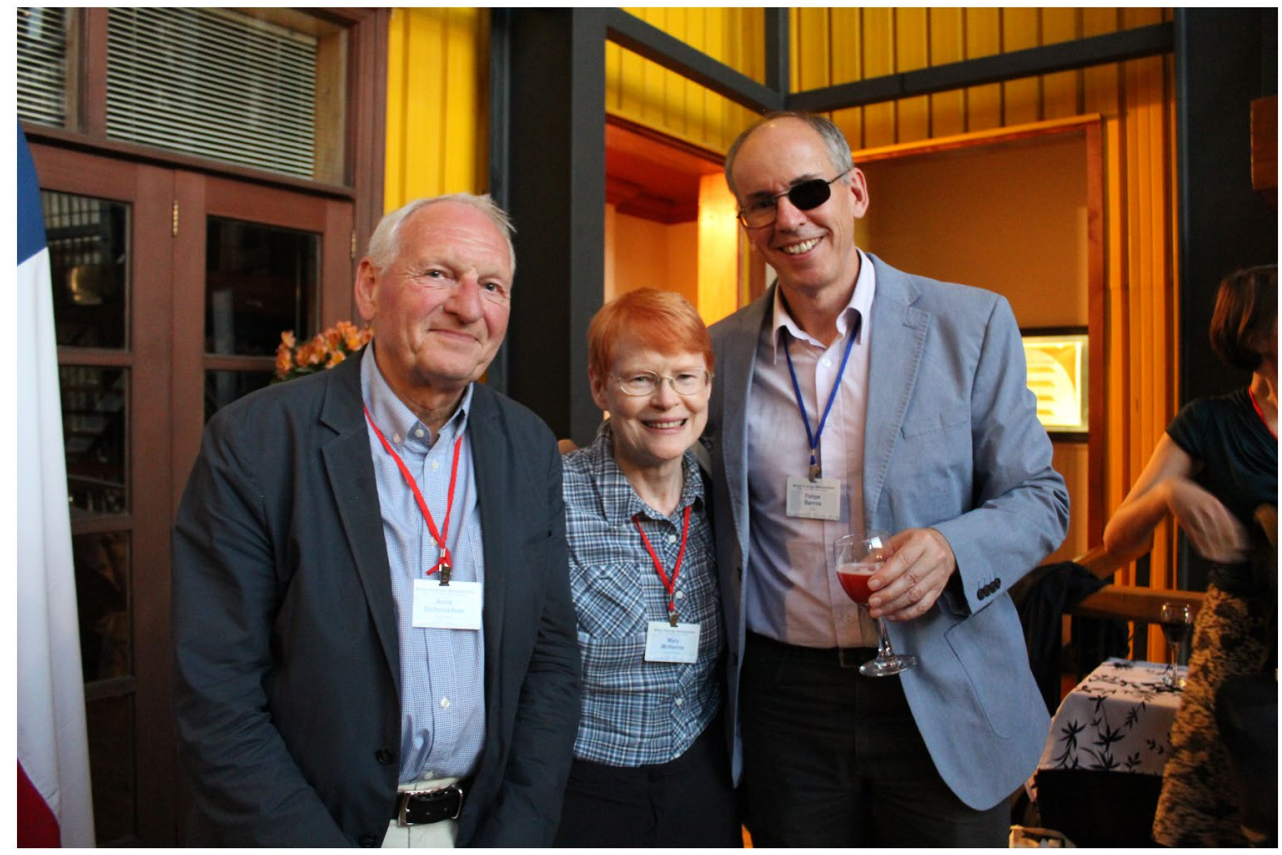

FIG URE 4 Arne Schousboe, Mary McKenna, and Felipe Barros at the opening reception for the 13th ICBEM meeting in Valdivia 2018

Fernández, Ignacio Fernández-Moncada, Bredford Kerr, Iván Ruminot, Pamela Sandoval and Alejandro San Martín for their enthusiasm, excellent organization, and their spirit of warmth and hospitality that made all the attendees feel welcome at the meeting venue and in beautiful Valdivia.

We would like to express our thanks for financial support from the ISCBFM, US PHS (NIH grant 1R13 NS106919-01) from the National Institute of Neurological Diseases and Stroke, the ISN Conference Committee, and Wiley-Blackwell, USA, Colun, Chile, and Conicyt PFB-01, Chile, without which this conference would not have been possible.

This special issue edited by Arne Schousboe, Mary McKenna, and L. Felipe Barros contains 14 peer-reviewed manuscripts from invited speakers who participated in this conference (Figure 4).

All the participants are looking forward to the 14th International Conference on Brain Energy Metabolism organized by In-Young Choi and Gerry Dienel that will be at Sea Pines Resort in Hilton Head, South Carolina, USA, from October 20-23, 2020, immediately before the SFN meeting. More information can be found at the conference website http://icbem2020.org/. We hope to meet everyone there for another highly stimulating and interactive meeting.

L. Felipe Barros Arne Schousboe Mary C. McKenna

\section{ORCID}

Arne Schousboe (iD https://orcid.org/0000-0001-9600-402X

Mary C. McKenna (iD https://orcid.org/0000-0002-5236-3853

How to cite this article: Barros LF, Schousboe A, McKenna MC. 13th International Conference on Brain Energy Metabolism: "How Metabolism Dictates Neurotransmission, Function and Behavior". J Neuro Res. 2019;97:849-853. https ://doi.org/10.1002/jnr.24445 